\title{
Analisis Kepuasan Kerja Karyawan Melalui Faktor-Faktor Quality of Work Life (QWL) pada PT. Pertamina (Persero) Perkapalan
}

\author{
Lindawati Kartika \\ Departemen Manajemen, Fakultas Ekonomi dan Manajemen \\ Institut Pertanian Bogor \\ Kampus Dramaga, Bogor, 16680 \\ Email: lindawati.kartika@gmail.com \\ Syamsul Maarif \\ Departemen Teknik Industri,Fakultas Teknologi Pertanian \\ Institut Pertanian Bogor \\ Kampus Dramaga, Bogor, 16680
}

\begin{abstract}
PT. Pertamina (Persero) Shipping as shipping division of PT. Pertamina (Persero) since 1959 is affecting by a new transformation strategy of PT. Pertamina, as holding, to face the oil and gas regulation - UU No. 22 year 2001, which change Indonesian oil market from monopoly into competitive market. As competitiveness strategy, the transformation is a necessary condition to achieve PT. Pertamina goal to be world class Oil Company. Employee commitments to service and performance quality are critical factors to achieve its goal, which human resources quality will be improved by providing employee satisfaction. The research objectives at PT. Pertamina (Persero) Shipping were (1) to identify the level of employee satisfaction, (2) to analyze the Quality of Work Life (QWL) , (3) to identify the factor of QWL which influence employee satisfaction, and (4) to identify the factors need to be improve to achieve employee satisfaction. The primary and secondary data were collected from the company. The primary data was collected using interviewed by likert scale questionnaires. And the research samples are 187 respondents which taken from 323 population of employee at PT. Pertamina (Persero) Shipping by cluster random sampling technique at 5\% standard error, and analyzed by Structural Equation Modeling (SEM). The study showed employee satisfaction level is good, which indicated by 3,70 score of total value of turnover, absenteeism, age, job level and organization size and 3,63 score on average value of all $Q W L$ variables. The SEM analysis showed job satisfaction variables such as communication, safety and conflict resolutions are influencing QWL. Other QWL factors were identify to be improve, by order are health, career development, employee participation, adequate compensation, pride and job security.

Keywords: Pertamina Shipping, Quality of Work Life, Structural Equation Modeling (SEM), The employee's work satisfaction
\end{abstract}




\section{Pendahuluan}

PT. Pertamina (Persero) Perkapalan khususnya senantiasa meningkatkan kualitasnya agar dapat unggul dalam bersaing dengan perusahaan-perusahaan kompetitornya. Oleh karena itu perusahaan berusaha untuk selalu meningkatkan kualitas pelayanan. Pelayanan yang berkualitas hanya dapat diperoleh dari sumber daya manusia yang memiliki kualitas yang tinggi. Seperti halnya perusahaan lainnya, PT. Pertamina (Persero) Perkapalan berupaya untuk meningkatkan kepuasan karyawan sehingga dapat meningkatkan kualitas sumber daya manusia yang dimilikinya.

Kepuasan merupakan hal yang bersifat individual, setiap individu memiliki tingkat kepuasan yang berbeda-beda, sehingga pengukurannya pun sangat bervariasi. Selain itu tolak ukur yang mutlak dalam mengukur tingkat kepuasan tidak ada (Hasibuan, 2003), oleh karena itu diperlukan suatu cara dalam mengukur tingkat kepuasan karyawan suatu perusahaan. Salah satu cara dalam mengukur tingkat kepuasan karyawan adalah dengan mengetahui perasaan karyawan terhadap aspek-aspek pekerjaannya (Quality of Work Life/ QWL), karena QWL merupakan upaya untuk mencapai kinerja yang unggul, produktivitas yang tinggi dan upaya untuk mencapai kepuasan diri dan lingkungan kerja yang optimal (Arifin, 1999). Salah satu tujuan QWL adalah untuk meningkatkan kepuasan karyawan terhadap pekerjaannya. Oleh karena itu dengan mengetahui QWL diharapkan dapat memberikan gambaran mengenai tingkat kepuasan karyawan, adapun faktor-faktor QWL yang dapat digunakan dalam mengukur tingkat kepuasan karyawan menurut Cascio (2006) yaitu melalui tingkat partisipasi karyawan, pengembangan karir, penyelesaian konflik, komunikasi, kesehatan kerja, keselamatan kerja, lingkungan yang aman, kompensasi yang layak, serta faktor kebanggan terhadap organisasi.

Pihak manajemen sering berupaya meningkatkan kepuasan karyawan melalui perbaikan gaji dan upah, hal tersebut mungkin masih bisa diterima pada taraf tertentu karena dengan gaji tersebut karyawan dapat memenuhi kebutuhan hidupnya. Tetapi kenyataannya gaji yang tinggi tidak selalu membuat seorang karyawan memperoleh kepuasan terhadap pekerjaannya (As'ad, 2005). Oleh karena itu pihak manajemen perlu mengetahui faktor-faktor apa saja yang dapat mempengaruhi kepuasan karyawan. Dengan mengetahui kepuasan karyawan terhadap faktor-faktor Quality of Work Life (QWL) diharapkan pihak manajemen memperoleh jawaban mengenai faktorfaktor apa saja yang sekiranya mempengaruhi kepuasan karyawan sehingga perusahaan dapat meningkatkan kepuasan para karyawannya yang pada akhirnya dapat membantu perusahaan untuk mencapai tujuan-tujuannya. Agar lebih terarah penelitian ini dibatasi dengan ruang lingkup sebagai berikut : (1) Quality of Work Life yang dibahas adalah faktor-faktor QWL berdasarkan Cascio meliputi faktor partisipasi karyawan, pengembangan karir, penyelesaian konflik, komunikasi, kesehatan kerja, keselamatan kerja, lingkungan yang aman, kompensasi yang layak dan kebanggaan (Cascio, 2006), (2) Kepuasan kerja yang diteliti disini adalah faktor kepuasan kerja menurut Davis dan Newstroom (1985) terdiri dari turn over, tingkat ketidakhadiran (absensi), tingkat pekerjaan, umur dan ukuran organisasi dan (3) Penelitian difokuskan pada karyawan PT Pertamina (Persero) Perkapalan yaitu pada analisa permasalahan kepuasan kerja karyawan melalui faktor-faktor yang QWL. 
Tujuan penelitian ini adalah : (1) Menganalisis kepuasan kerja di PT Pertamina (Persero) Perkapalan, (2) Menganalisis QWL di PT Pertamina (Persero) Perkapalan, (3) Menganalisis pengaruh faktor-faktor QWL terhadap kepuasan karyawan dan (4) Mengetahui faktor-faktor QWL mana saja yang harus ditingkatkan untuk mencapai kepuasan karyawan.

\section{Metode Penelitian}

Gambar 1 akan menjelaskan model analisis dalam penelitian mengenai kepuasan karyawan melalui faktor-faktor QWL.

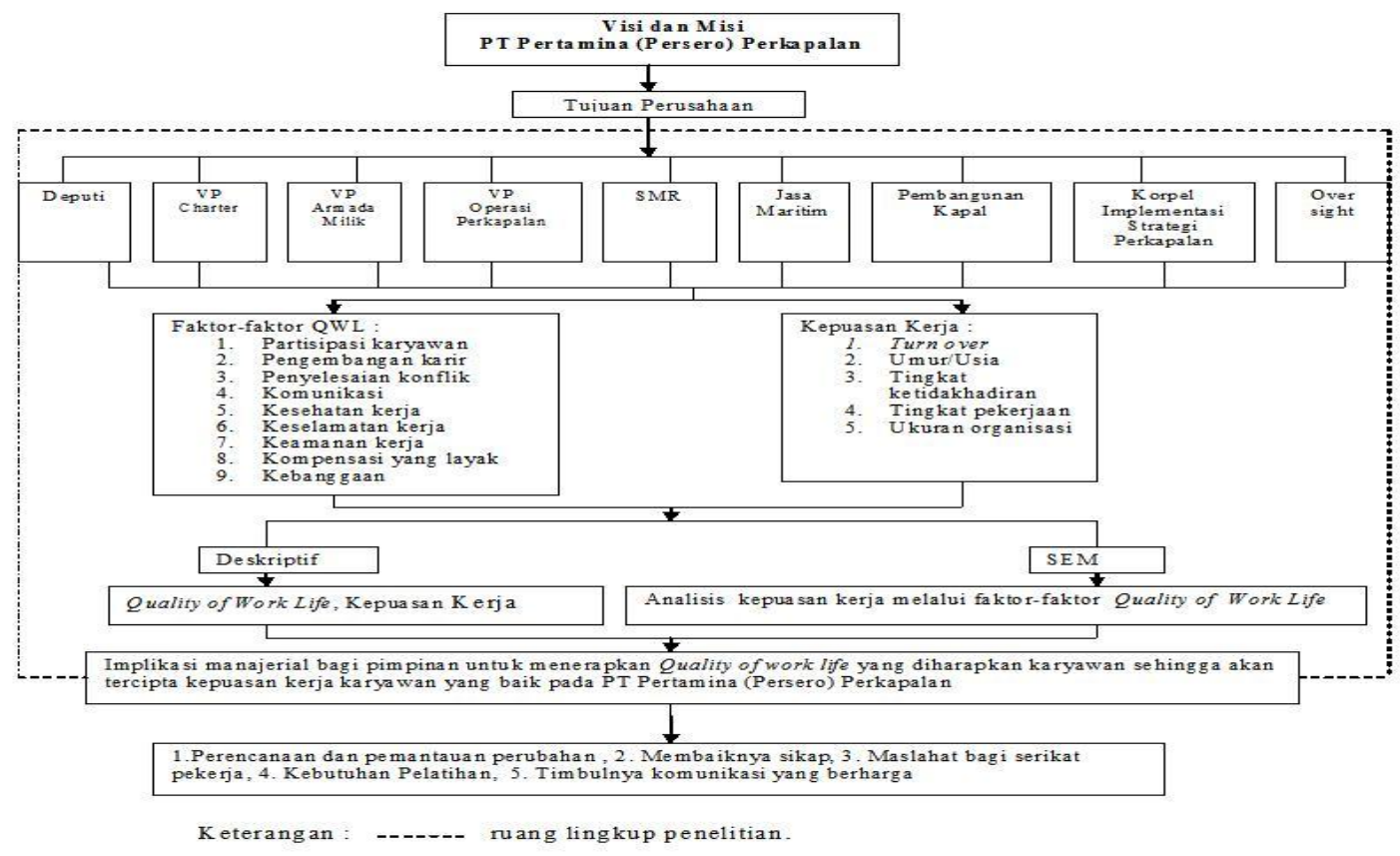

Gambar 1. Kerangka Pemikiran Analisis kepuasan Kerja karyawan melalui faktor- faktor $Q W L$

Kegiatan penelitian ini dilaksanakan pada PT Pertamina (Persero) Perkapalan yang berada di kawasan Jakarta Utara. Tepatnya berlokasi di Jalan Yos Sudarso No. 32-34 Tanjung Prio Jakarta Utara Pada bulan Januari 2009.

Menurut Hasan (2002) populasi adalah keseluruhan dari semua objek atau individu yang memiliki karakteristik tertentu, jelas dan lengkap yang akan diteliti. Populasi dari penelitian ini adalah PT Pertamina (Persero) Perkapalan sebanyak 323 orang. Metode pengambilan sampel untuk penelitian ini dilakukan menggunakan teknik Non probability sampling yaitu Cluster quota Sampling merupakan teknik sampling yang digunakan pada populasi yang mempunyai anggota atau unsur yang homogen dan berstrata secara proporsional. Menurut Umar (2005) untuk ukuran populasi yang masing-masing ukurannya tiap sub populasi adalah berbeda maka untuk mengambil sampel sebesar 179 orang tidak dapat menggunakan cara yang proporsional, melainkan harus sebanding dengan jumlah subpopulasinya, sehingga perlu dicari faktor pembanding dari setiap sub populasi yang sering disebut sample fraction ( $f$ ) dengan cara membandingkan jumlah seluruh elemen populasi sehingga didapat masing-masing sample fraction-nya. Hasil hitungnya untuk mendapatkan sampel dari tiap-tiap subpopulasi disajikan berikut ini (hasilnya telah dibulatkan) Berdasarkan 
rumus Slovin tersebut, untuk ukuran sampel yang didasarkan pada taraf $5 \%$ atau taraf kepercayaan 5\% dari populasi yang berjumlah 323 orang, dapat ditentukan jumlah sampel yang representatif sebanyak 179 orang. Pengambilan sampel dapat dijelaskan pada Tabel 1.

Tabel 1. Pengambilan sampel secara Cluster quota sampling dengan jumlah elemen tiap populasi berbeda.

\begin{tabular}{|c|c|c|c|c|}
\hline No & Divisi & Nilai fraction(f) & Nilai Sub Populasi & $\begin{array}{l}\text { Sampel } \\
\text { diambil }\end{array}$ \\
\hline 1 & Deputi Direktur/SVP Perkapalan & $2 / 323=0.006$ & 2 & 1 \\
\hline 2 & VP Charter & $30 / 323=0.093$ & 30 & 17 \\
\hline 3 & VP Armada Milik & $104 / 323=0.322$ & 104 & 58 \\
\hline 4 & VP Operasi Perkapalan & $69 / 323=0.214$ & 69 & 38 \\
\hline 5 & $\begin{array}{l}\text { Safety Management } \\
\text { Representative }\end{array}$ & $18 / 323=0.055$ & 18 & 10 \\
\hline 6 & Jasa Maritim & $53 / 323=0.164$ & 53 & 29 \\
\hline 7 & Pembangunan Kapal & $17 / 323=0.053$ & 17 & 10 \\
\hline 8 & $\begin{array}{l}\text { Korpel Implementasi Strategi } \\
\text { Perkapalan }\end{array}$ & $24 / 323=0.074$ & 24 & 13 \\
\hline \multirow[t]{2}{*}{9} & Oversight & $6 / 323=0.019$ & 6 & 3 \\
\hline & Total & 1.00 & 323 & 179 \\
\hline
\end{tabular}

Sumber : Umar (2005)

Berdasarkan pendapat Hair et al. (1998) bahwa ukuran sampel untuk pengujian model dengan menggunakan SEM adalah 100-200 sampel untuk teknik maximum Likelihood estimation. Berdasarkan hal tersebut penelitian ini menggunakan 179 sampel untuk dapat memenuhi persyaratan besaran sampel untuk analisis SEM.

Pengumpulan data yang relevan dalam penelitian ini dilakukan dengan mengumpulkan data atau informasi berupa data primer dan data sekunder. Adapun data primer dapat diperoleh dengan melakukan pengamatan langsung di lapangan, wawancara dengan pihak-pihak yang terkait dengan perusahaan yaitu pihak perusahaan yang berkaitan dengan sumberdaya manusia serta melalui hasil pengisian kuesioner. Data sekunder tentang gambaran umum perusahaan, mencakup data tentang sejarah perkembangan perusahaan, struktur organisasi perusahaan, ketenagakerjaan karyawan diperoleh dari literatur-literatur dan laporan-laporan yang dimiliki oleh perusahaan. Wawancara dibantu dengan instrumen penelitian yaitu kuesioner yang diberikan kepada responden, pengamatan langsung, dan studi kepustakaan. Jawaban responden terhadap kuesioner dinilai dengan menggunakan skala Likert, di mana:

Bobot nilai 1 = sangat tidak setuju.

Bobot nilai 2 = tidak setuju.

Bobot nilai 3 = kurang setuju.

Bobot nilai $4=$ setuju.

Bobot nilai 5 = sangat setuju.

Rata-rata tertimbang digunakan untuk mengelompokkan jawaban responden terhadap masing-masing kriteria (skala 1-5) seperti pada bobot nilai pengumpulan data. Kemudian jumlah responden dikelompokkan di dalam setiap kriteria dikalikan dengan bobotnya, lalu hasil perkalian di dalam setiap kriteria dijumlahkan kemudian 
dibagi dengan jumlah respondennya, sehingga didapat suatu nilai rata-rata tertimbang yang berada pada skala 1-5. Dengan rumus sebagai berikut:

\begin{tabular}{lllllll}
\hline $\mathrm{X}_{\mathrm{i}}$ & 1 & 2 & 3 & 4 & 5 & \\
\hline $\mathrm{f}_{\mathrm{i}}$ & $\mathrm{f}_{1}$ & $\mathrm{f}_{2}$ & $\mathrm{f}_{3}$ & $\mathrm{f}_{4}$ & $\mathrm{f}_{5}$ & $\Sigma \mathrm{f}_{\mathrm{i}}$ \\
\hline
\end{tabular}

$$
\bar{X}=\frac{\sum_{i=1}^{n} X_{i} f_{i}}{\sum_{i=1}^{n} f_{i}}
$$

Keterangan : $X_{i}=$ skor butir ke- $\mathrm{i}$

$f_{i}=$ frekuensi skor ke-i

Dari hasil nilai rata-rata tertimbang kemudian ditentukan rentang skala tiap komponen dengan menggunakan rumus rentang skala (1-5):

$$
R S=\frac{(\mathrm{m}-1)}{\mathrm{m}}
$$

dimana : $m=$ jumlah alternatif jawaban tiap item

Model persamaan struktural atau SEM adalah sekumpulan teknik-teknik statistikal yang memungkinkan pengujian sebuah rangkaian hubungan yang relatif rumit secara simultan (Ferdinand, 2002).

Hubungan yang rumit itu dapat dibangun antar satu atau beberapa faktor dependen dengan satu atau beberapa faktor dependen dengan satu atau beberapa faktor independen. Masing-masing faktor dependen dan independen dapat berbentuk faktor (atau konstruk, yang dibangun dari beberapa faktor faktor). Faktor-faktor itu dapat berbentuk sebuah faktor tunggal yang di observasi atau diukur langsung dalam sebuah proses penelitian. Metode SEM digunakan untuk menganalisis hubungan sebab akibat (kausal) yang rumit, dimana didalamnya terdapat faktor laten dan faktor faktor. SEM menggambarkan keterkaitan hubungan linear secara simultan faktor-faktor pengamatan, yang sekaligus melibatkan faktor laten yang tidak dapat diukur secara langsung.

Secara umum teknik didalam SEM terbagi menjadi dua yaitu :

1. Mengestimasi beberapa persamaan yang saling berhubungan secara simultan (Structural Model)

2. Mempresentasikan faktor konstruk berdasarkan faktor observed (Measurement model)

Pada model pengukuran ini dapat dilihat berapa kontribusi dan bagaimana signifikansi dari masing-masing faktor faktor terhadap faktor laten. Tahap-tahap yang dilakukan dalam menyusun model persamaan struktural adalah: mengembangkan model berdasarkan teori, membangun diagram linta(path analysis), konversi diagram lintas ke persamaan, mengidentifikasi model, penetapan kriteria kesesuaian model, dan interpretasi dan modifikasi model.

Faktor-faktor internal kepuasan kerja dengan faktor faktor terdiri dari : 
$Y_{1}=$ Turn Over

$\mathrm{Y}_{2}=$ Umur

$\mathrm{Y}_{3}=$ Tingkat Ketidakhadiran

$\mathrm{Y}_{4}=$ Tingkat Pekerjaan

$\mathrm{Y}_{5}=$ Ukuran Organisasi

Faktor Quality of Work Life dikorelasikan dengan kepuasan kerja dengan komponen pembentuknya.

1. Partisipasi kerja

$\mathrm{X} 1$ = Kerjasama karyawan dalam tim.

$\mathrm{X} 2$ = Partisipasi karyawan dalam rapat.

X3 = Peningkatan kualitas tim.

2. Pengembangan karier

$\mathrm{X}_{4}=$ Perlindungan jabatan .

$\mathrm{X}_{5}=$ Pelatihan/pendidikan.

$X_{6}=$ Penilaian kegiatan.

$\mathrm{X}_{7}=$ Promosi dari dalam.

3. Komunikasi

$\mathrm{X}_{8}=$ Pertemuan tatap muka.

$X_{9}=$ Pertemuan kelompok

$\mathrm{X}_{10}=$ Publikasi.

4. Keselamatan Kerja

$\mathrm{X}_{11}=$ Komite keselamatan.

$X_{12}=$ Tim penolong gawat darurat.

$\mathrm{X}_{13}=$ Program keselamatan kerja.

5. Kebanggaan

$\mathrm{X}_{14}=$ Identitas perusahaan.

$\mathrm{X}_{15}=$ Partisipasi kemasyarakatan.

$X_{16}=$ Kepedulian lingkungan.

6. Kesehatan Kerja

$\mathrm{X}_{17}=$ Pusat kesehatan.

$\mathrm{X}_{18}=$ Pusat kesehatan gigi.

$X_{19}=$ Program pusat senam \& kebugaran.

$X_{20}=$ Program rekreasi.

$\mathrm{X}_{21}=$ Program konseling.

7. Keamanan Kerja

$\mathrm{X}_{22}=$ Tidak ada pemberhentian karyawan tetap.

$X_{23}=$ Program pensiun.

8. Kompensasi yang layak

$\mathrm{X}_{24}=$ Gaji.

$\mathrm{X}_{25}=$ Keuntungan yang kompetitif.

9. Penyelesaian konflik

$\mathrm{X}_{26}=$ Keterbukaan.

$\mathrm{X}_{27}=$ Proses penyampaian keluhan secara formal.

$\mathrm{X}_{28}=$ Pertukaran pendapat/proses banding. 
Berdasarkan tujuan yang telah ditetapkan, maka dirumuskan hipotesis sebagai berikut:

1. Ada pengaruh signifikan antara Partisipasi karyawan yang baik terhadap kepuasan kerja karyawan di PT Pertamina (Persero) Perkapalan.

2. Ada pengaruh signifikan antara faktor Pengembangan karir yang terencana dan profesional terhadap kepuasan kerja karyawan di PT Pertamina (Persero) Perkapalan.

3. Ada pengaruh signifikan antara faktor kemampuan dalam penyelesaian konflik yang baik terhadap kepuasan kerja karyawan di PT Pertamina (Persero) Perkapalan.

4. Ada pengaruh signifikan antara faktor komunikasi yang baik antara pihak-pihak yang terkait atau kelompok terhadap kepuasan kerja karyawan di PT Pertamina (Persero) Perkapalan.

5. Ada pengaruh signifikan antara faktor Kesehatan kerja yang memadai terhadap kepuasan kerja karyawan di PT Pertamina (Persero) Perkapalan.

6. Ada pengaruh signifikan antara faktor Keselamatan kerja yang relevan terhadap kepuasan kerja karyawan di PT Pertamina (Persero) Perkapalan.

7. Ada pengaruh signifikan antara faktor lingkungan yang aman terhadap kepuasan kerja karyawan di PT Pertamina (Persero) Perkapalan.

8. Ada pengaruh signifikan antara faktor kompensasi yang layak terhadap kepuasan kerja karyawan di PT Pertamina (Persero) Perkapalan.

9. Ada pengaruh signifikan antara kebanggaan pada organisasi terhadap kepuasan kerja karyawan di PT Pertamina (Persero) Perkapalan

10. Ada pengaruh signifikan antara Quality of Work Life terhadap kepuasan kerja karyawan di PT Pertamina (Persero) Perkapalan.

Uji hipotesis dalam SEM langsung dapat dilihat dari fit indeks model hasil estimasi. Hipotesis yang diuji adalah: $\mathrm{H}_{0}: \Sigma=\Sigma(\theta)$ lawan $\mathrm{H}_{1}: \Sigma \neq \Sigma(\theta)$

dengan $\Sigma$ adalah matriks input, sedangkan $\Sigma(\theta)$ adalah matriks hasil dugaan. Hipotesis $\mathrm{H}_{0}$ menyatakan bahwa matriks dugaan dari model SEM mampu mereprentasikan data dengan baik, sedangkan $\mathrm{H}_{1}$ sebaliknya.

\section{Hasil Penelitian}

III.1. Analisis Persepsi Karyawan Terhadap Faktor-faktor Quality of Work Life

Penilaian responden tentang faktor partisipasi karyawan, pengembangan karier, komunikasi, keselamatan kerja, kebanggaan, kesehatan kerja, keamanan kerja, kompensasi yang layak dan penyelesaian konflik yaitu sebagian besar penilaian berada pada jawaban positif, hal ini ditunjukkan dengan persepsi setiap faktor yaitu partisipasi karyawan di perusahaan sudah baik, terlihat dari kerjasama karyawan dalam tim, partisipasi karyawan dalam rapat maupun untuk peningkatan kualitas tim. Apabila partisipasi dilakukan dengan baik, dua hasilnya yang terbaik adalah perubahan dan keikatan terhadap tujuan yang mendorong timbulnya prestasi lebih baik. Keterlibatan mental dan emosional orang-orang dalam situasi kelompok yang mendorong mereka untuk memberikan kontribusi kepada tujuan kelompok dan berbagi tanggung jawab untuk pencapaian itu. Persepsi mengenai pengembangan karir mengindikasikan bahwa program pengembangan karir di perusahaan sudah baik, dilihat dari perlindungan jabatan, pelatihan/pendidikan, penilaian kegiatan serta promosi dari dalam. Persepsi mengenai faktor komunikasi adalah positif, situasi tersebut mengindikasikan bahwa 
proses komunikasi di perusahaan sudah baik, dilihat dari pertemuan tatap muka, pertemuan kelompok dan komunikasi. Persepsi mengenai faktor keselamatan kerja mengindikasikan bahwa penerapan sistem manajemen keselamatan kerja di perusahaan sudah baik, sehingga citra organisasi terhadap kinerjanya akan semakin meningkat, dan tentu ini akan meningkatkan kepercayaan dan kenyamanan baik pegawai maupun pelanggan. Persepsi mengenai faktor kebanggaan mengindikasikan bahwa kebanggaan pegawai terhadap perusahaan serta apa yang telah dilakukan perusahaan sejauh ini dinilai baik, sehingga pada akhirnya diharapkan dengan adanya kebanggaan terhadap perusahaan, pegawai lebih loyal dan memiliki komitmen kerja yang baik. Persepsi terhadap faktor kesehatan kerja mengindikasikan bahwa perusahaan mementingkan program kesehatan kerja bagi pegawainya, karena dengan pegawai yang sehat tentunya beban perusahaan akan lebih sedikit, selain itu juga produktivitas pegawai akan meningkat seiring dengan kondisi pegawai yang sehat baik secara fisik, pikiran, emosional ataupun spiritual.Persepsi mengenai faktor keamanan kerja mengindikasikan bahwa gambaran keamanan kerja belum terwujud secara maksimal, dilihat dari faktor tidak ada pemberhentian karyawan tetap dan program pensiun yang ada di perusahaan.Persepsi mengenai faktor mengindikasikan bahwa gambaran kompensasi yang layak secara umum sudah cukup baik penerapannya di perusahaan, dilihat dari faktor gaji dan keuntungan yang kompetitif yang mengindikasikan bahwa gaji yang diterima pegawai di perusahaan sudah memenuhi standar hidup masing-masing pekerja. Persepsi mengenai penyelesaian konflik ini mengindikasikan bahwa konflik yang ada di perusahaan selama ini selalu dapat diselesaikan dengan jalan terbaik (win-win solution) yang merupakan jalan terbaik dari setiap permasalahan yang dihadapi perusahaan. Hasil analisis deskriptif Quality of Work Life secara lengkap terdapat pada Tabel 2.

\section{Tabel 2. Hasil Analisis Deskriptif Quality of Work Life}

\begin{tabular}{llll}
\hline No & Pernyataan Terhadap Faktor Quality Of Work Life & Mean & Ket \\
\hline 1 & Persepsi Karyawan terhadap Faktor Partisipasi Kerja & 3.92 & Setuju \\
2 & Persepsi Karyawan terhadap Faktor Pengembangan Karier & 3.59 & Setuju \\
3 & Persepsi Karyawan terhadap Faktor Komunikasi & 3.92 & Setuju \\
4 & Persepsi Karyawan terhadap Faktor Keselamatan Kerja & 3.64 & Setuju \\
5 & Persepsi Karyawan terhadap Faktor Kebanggaan & 3.71 & Setuju \\
6 & Persepsi Karyawan terhadap Faktor Kesehatan Kerja & 3.58 & Setuju \\
7 & Persepsi Karyawan terhadap Faktor Keamanan Kerja & 3.13 & Cukup Setuju \\
8 & Persepsi Karyawan Terhadap Faktor Kompensasi yang layak & 3.56 & Setuju \\
9 & Persepsi Karyawan Terhadap Faktor Penyelesaian konflik & 3.44 & Setuju \\
\hline \multicolumn{2}{c}{ Rata-rata } & 3.61 & Setuju \\
\hline
\end{tabular}

\section{III.2. Analisis Persepsi Karyawan Terhadap Faktor Kepuasan Kerja}

Penilaian responden terhadap faktor turn over, ketidakhadiran, usia, tingkat pekerjaan dan ukuran organisasi sebagian besar penilaian responden berada pada jawaban positif, situasi tersebut mengindikasikan bahwa gambaran faktor kepuasan kerja melalui faktor tersebut secara umum sudah baik penerapannya di perusahaan, dalam arti perusahaan memiliki tingkat turn over yang kecil, pegawai di perusahaan memiliki tingkat ketidakhadiran yang kecil, tingkat pertambahan usia pekerja secara umum sudah baik dalam arti semakin bertambahnya usia, maka perihal seperti tantangan, kepuasan bekerja, pengalaman, kemampuan adaptasi dan produktifitas kerja meningkat, demikian juga dengan persepsi terhadap faktor tingkat 
pekerjaan, yaitu pegawai di perusahaan merasakan bahwa beban pekerjaan mereka pada umumnya sudah sesuai dengan jabatan atau tugas yang mereka dapat lakukan sesuai kompetensi, serta persepsi mengenai ukuran organisasi mengindikasikan bahwa gambaran ukuran organisasi pegawai secara umum sudah baik penerapannya di perusahaan, dalam arti pegawai di perusahaan dengan ukuran organisasi yang seperti sekarang ini, dapat merepresentasikan kepuasan kerja. Hasil analisis deskriptif kepuasan kerja secara lengkap terdapat pada Tabel 3.

Tabel 3. Analisis Persepsi Karyawan Terhadap Faktor Kepuasan Kerja

\begin{tabular}{clcc}
\hline No & \multicolumn{1}{c}{ Pernyataan Terhadap Faktor Kepuasan Kerja } & Mean & Ket \\
\hline 1 & Persepsi Karyawan terhadap Faktor Turn Over & 3.59 & Setuju \\
2 & Persepsi Karyawan terhadap Faktor Ketidakhadiran & 3.99 & Setuju \\
3 & Persepsi Karyawan terhadap Faktor Usia & 3.81 & Setuju \\
4 & Persepsi Karyawan terhadap Faktor Tingkat Pekerjaan & 3.63 & Setuju \\
5 & Persepsi Karyawan terhadap Faktor Ukuran Organisasi & 3.52 & Setuju \\
\hline Rata-rata & 3.71 & Setuju \\
\hline
\end{tabular}

III.3. Hasil Pengukuran Model Struktural Analisis Kepuasan Kerja dengan Faktor -faktor Quality of Work Life.

Berdasarkan hasil analisis dengan menggunakan metode SEM dengan bantuan software Lisrell 8.72 diperoleh bahwa pengaruh dari sembilan faktor quality of work life terhadap kepuasan kerja pegawai hanya komunikasi dan penyelesaian konflik yang memiliki pengaruh positif yang kuat dengan kepuasan kerja karyawan. Sedangkan untuk keselamatan kerja berpengaruh tetapi nilainya negatif. Bila dipelajari, kondisi ini dapat disebabkan beberapa kemungkinan penyebab. Kemungkinan pertama, nilai dari faktor-faktor QWL tersebut memang merupakan faktor yang tidak terlalu berhubungan dan berpengaruh erat dengan peningkatan kepuasan kerja karyawan. Dengan demikian, meski faktor-faktor QWL lainnya tersebut pada kenyataannya sudah dilaksanakan dengan baik, namun tidak membawa perubahan yang berarti pada kepuasan kerja karyawan. Kemungkinan kedua ialah disebabkan masih kurangnya sosialisasi ataupun internalisasi, sehingga nilai budaya tersebut masih sebatas diketahui atau dimengerti saja, belum menjadi suatu budaya yang terintegrasi dengan kehidupan kerja karyawan.

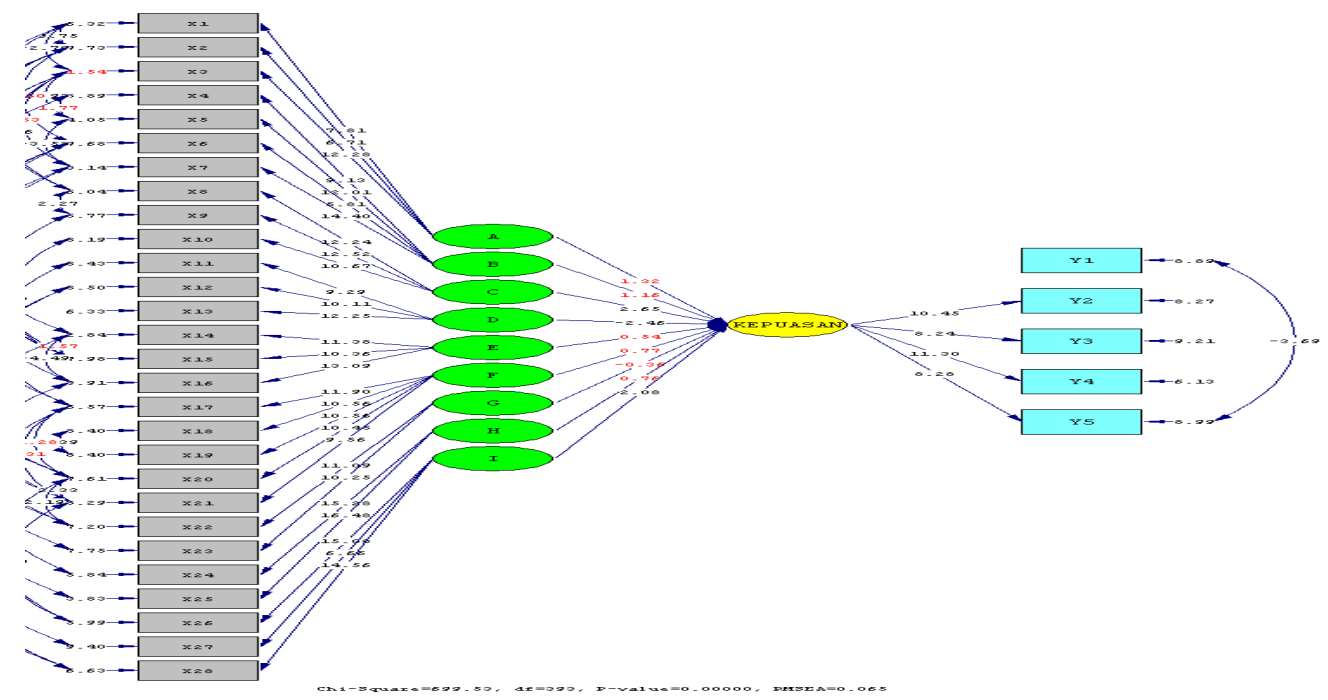

Gambar 2. Diagram Path $t$ Value Analisis Kepuasan Kerja Melalui Faktor-faktor QWL 
Berdasarkan hasil estimasi SEM dengan menggunakan Lisrell 8.72 diperoleh faktorfaktor QWL yang memiliki sedikit kontribusi dalam membentuk kepuasan kerja meliputi : kesehatan kerja, pengembangan karier, partisipasi karyawan, kompensasi yang layak, kebanggaan dan keamanan kerja. Namun harus tetap diperhatikan untuk menjaga keseimbangan kerja dalam jangka panjang.

Faktor-faktor QWL tersebut secara keseluruhannya apabila dapat dikelola dengan baik akan berdampak pada kepuasan kerja sehingga tingkat kehadiran karyawan tinggi, tingkat pekerjaan dimana pegawainya dengan tingkat pekerjaan yang lebih tinggi merasa lebih puas, turn over yang rendah, dan usia yaitu dimana pegawai semakin bertambah usianya maka cenderung merasa lebih puas.

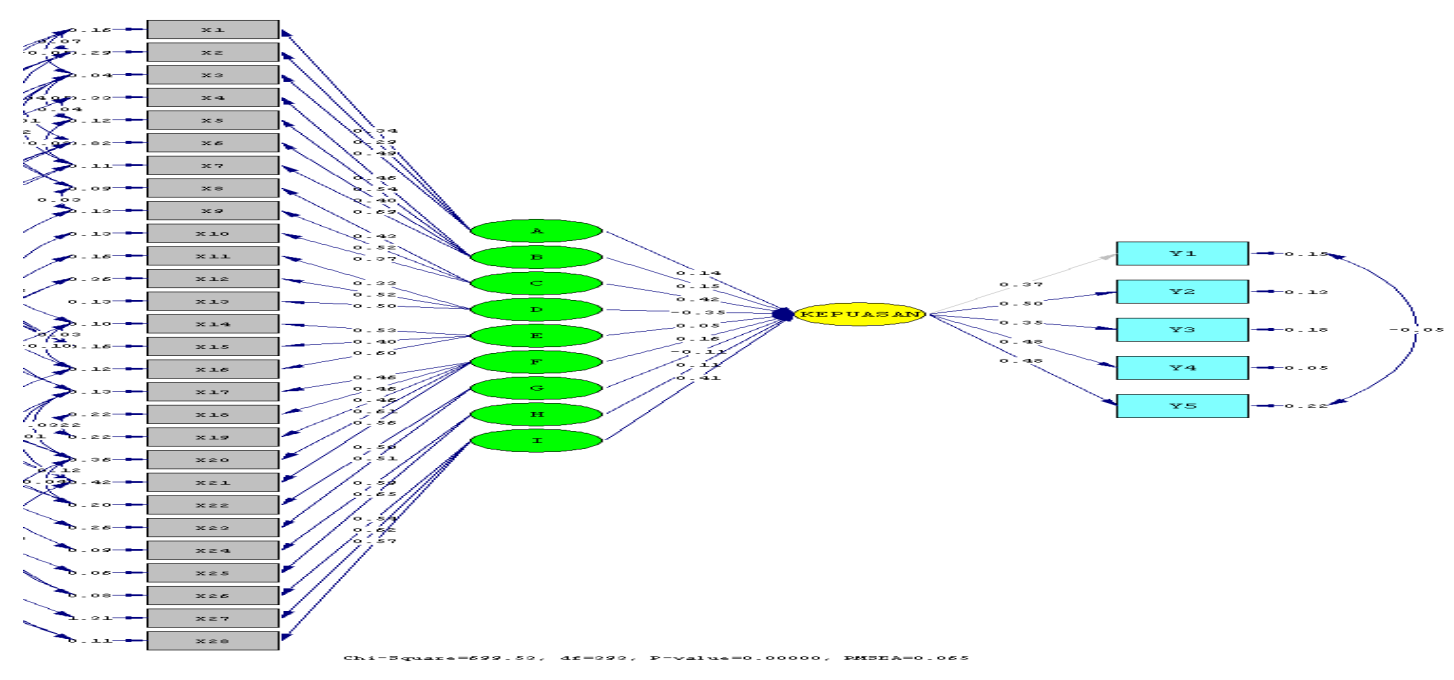

Gambar 3. Diagram Standardized Loading Factor Analisis Kepuasan Kerja Melalui Faktor-faktor QWL

Berdasarkan hasil analisis yang telah dilakukan, diketahui bahwa pengaruh dari sembilan faktor quality of work life terhadap kepuasan kerja pegawai hanya komunikasi dan penyelesaian konflik yang memiliki pengaruh positif yang kuat dengan kepuasan kerja karyawan. Sedangkan untuk keselamatan kerja berpengaruh tetapi nilainya negatif. Nilai masing-masing loading faktor tersebut dapat diperjelas dengan Tabel 4.

Tabel 4. Nilai Koefisien Masing-masing Hubungan Struktural

\begin{tabular}{clcc}
\hline No & \multicolumn{1}{c}{ Hubungan Antar Faktor } & Koefisien & nilai t > 1.96 \\
\hline 1 & Partisipasi Karyawan dengan kepuasan kerja & 0.14 & 1.32 \\
2 & Pengembangan karir dengan kepuasan kerja & 0.15 & 1.15 \\
3 & Komunikasi dengan kepuasan kerja & 0.42 & 2.65 \\
4 & Keselamatan kerja dengan kepuasan kerja & -0.35 & -2.46 \\
5 & Kebanggaan dengan kepuasan kerja & 0.05 & 0.54 \\
6 & Kesehatan kerja dengan kepuasan kerja & 0.15 & 0.77 \\
7 & Keamanan kerja dengan kepuasan kerja & -0.11 & -0.35 \\
8 & Kompensasi yang layak dengan kepuasan kerja & 0.11 & 0.78 \\
9 & Penyelesaian konflik dengan kepuasan kerja & 0.41 & 2.08 \\
\hline
\end{tabular}




\section{III.4. Implikasi Manajerial}

Berdasarkan hasil penelitian yang diperoleh, maka penulis mencoba merumuskan suatu konsep sebagai implikasi manajerial agar kepuaan kerja yang ingin dibangun dapat benar-benar menjadi bagian yang terintegrasi dari kehidupan kerja karyawan. Konsep ini bertajuk "Pertamina Work Satisfaction Re-Build". Konsep pembangunan kepuasan kerja PT Pertamina ini secara garis besar terdiri dari empat tahapan, yaitu tahap review, sosialisasi, internalisasi serta adaptasi dan pengembangan. Untuk lebih jelas, konsep ini dapat dilihat pada Gambar 4.

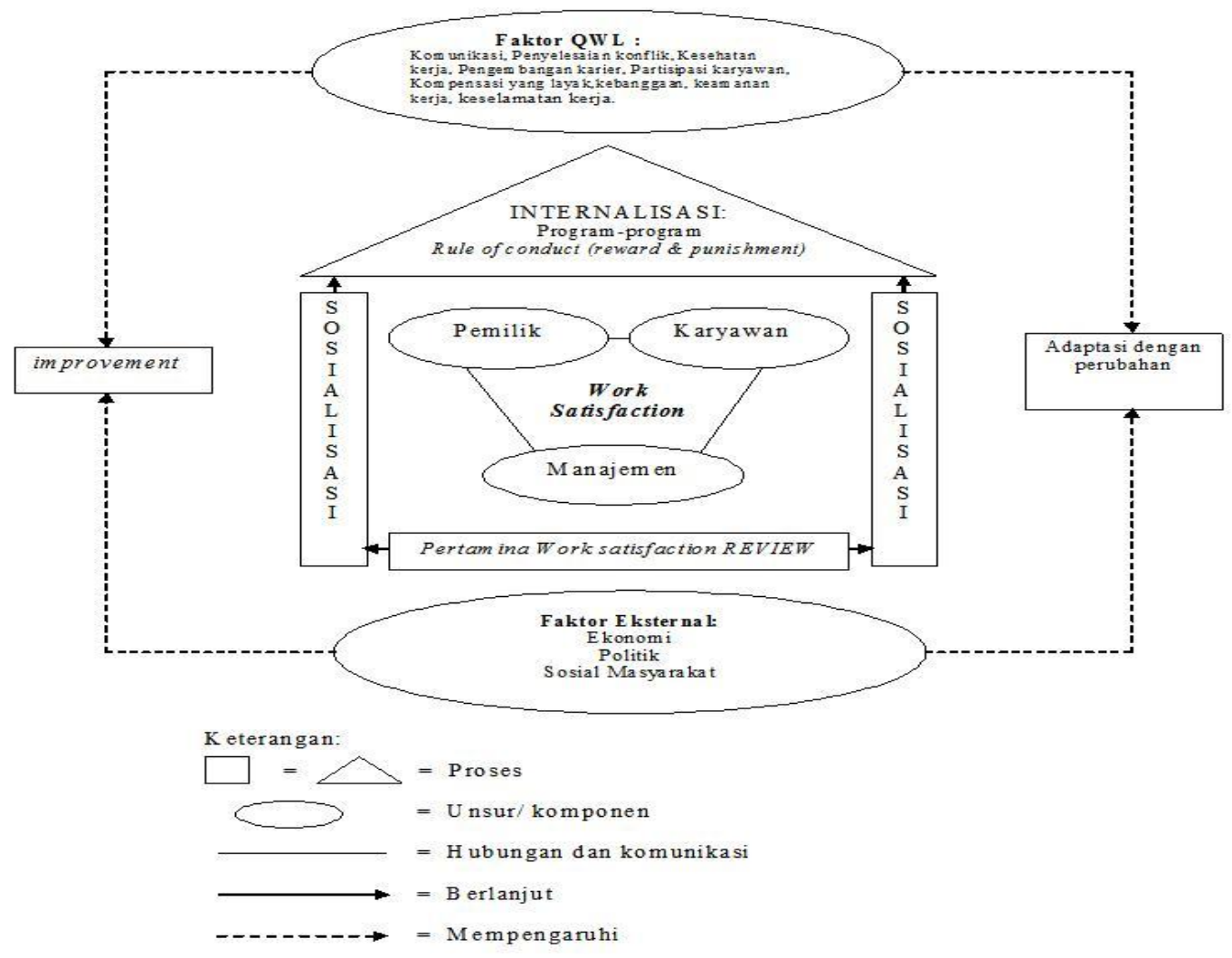

Gambar 4. Konsep Pertamina Work Satisfaction Re-build

\section{Kesimpulan}

Secara umum pegawai PT Pertamina (Persero) Perkapalan berada pada kategori puas. Hal tersebut didasarkan pada hasil nilai rataan yang diperoleh dari jawaban responden mengenai kepuasan mereka baik langsung maupun tidak langsung (melalui persepsi karyawan terhadap sembilan faktor quality of work life). Berdasarkan pernyataan langsung mengenai persepsi pegawai terhadap kepuasan kerja dari mulai nilai persepsi terbesar secara berturut-turut yaitu faktor ketidakhadiran, usia, tingkat pekerjaan, turn over dan ukuran organisasi.

Gambaran Quality of Work Life di PT Pertamina (Persero) Perkapalan secara umum dari sembilan faktor Cascio (2006) berdasarkan jawaban responden secara deskriptif menyatakan berada dalam persepsi baik, kemudian melalui nilai dari mulai yang tertinggi pada setiap faktor quality of work life adalah sebagai berikut: partisipasi 
karyawan, komunikasi, kebanggaan, keselamatan kerja, pengembangan karir, kesehatan kerja, penyelesaian konflik dan keamanan kerja.

Pengaruh quality of work life terhadap kepuasan kerja dari hasil pengolahan analisis structural equation modeling (SEM) diperlihatkan bahwa :

a. Kepuasan karyawan di PT Pertamina (Persero) Perkapalan hanya terdapat dua faktor QWL yang memiliki pengaruh signifikan positif terhadap kepuasan yaitu komunikasi dan penyelesaian konflik. Karyawan menilai bahwa komunikasi dan penyelesaian konflik merupakan hal yang dianggap berkontribusi besar terhadap kepuasan kerja mereka.

b. Kepuasan karyawan di PT Pertamina (Persero) Perkapalan terdapat satu faktor QWL yang memiliki pengaruh signifikan negatif terhadap kepuasan yaitu keselamatan kerja, dimana penilaian terhadap keselamatan kerja bagi karyawan head office tidak dianggap hal yang penting, karena sudah menggunakan prosedur yang standard dan tidak terlalu dikhawatirkan.

c. Faktor-faktor QWL yang memiliki sedikit kontribusi dalam membentuk kepuasan kerja meliputi : kesehatan kerja, pengembangan karier, partisipasi karyawan, kompensasi yang layak, kebanggaan dan keamanan kerja. Namun harus tetap diperhatikan untuk menjaga keseimbangan kerja dalam jangka panjang.

Faktor-faktor QWL tersebut secara keseluruhannya apabila dapat dikelola dengan baik akan berdampak pada kepuasan kerja sehingga tingkat kehadiran karyawan tinggi, tingkat pekerjaan dimana pegawainya dengan tingkat pekerjaan yang lebih tinggi merasa lebih puas, turn over yang rendah, dan usia yaitu dimana pegawai semakin bertambah usianya maka cenderung merasa lebih puas.

1. Faktor QWL yang perlu ditingkatkan untuk mencapai kepuasan kerja maksimal yaitu berdasarkan urutannya dari yang tertinggi adalah : Komunikasi, penyelesaian konflik, kesehatan kerja, pengembangan karier, partisipasi karyawan, kompensasi layak, kebanggaan, keamanan kerja dan keselamatan kerja.

\section{Daftar Pustaka}

Cascio, W.F. 2006. Managing Human Resources : Productivity, Quality of Work Life, Profits. $7^{\text {th }}$ Edition. McGraw-Hill Companies, Inc. USA.

Cushway, B. dan D. Lodge. 2002. Perilaku dan Desain Organisasi. Terjemahan. PT Elex Media Komputindo. Jakarta.

Creswell, John. 1994. Research Design, Quantitative \& Qualitative Approaches. Sage Publications.

Davis, K. 1984. Human Behavior at Work Organizational Behavior. Edisi ke-6. Tata McGraw-Hill. New Delhi.

Davis, K dan J.W. Newstrom. 1985. Perilaku Organisasi. Jilid 1, Edisi 7. Terjemahan. Erlangga. Jakarta.

Ferdinand, Augusty, 2002, Structural Equation Modeling Dalam Penelitian Manajemen Edisi 2, Semarang: BP UNDIP. 
Garson, G.D. 2000. Structural Equation Modelling. North Carolina State University. http: //www2.chass.ncsu.edu/garson/pa765/structur.htm [01 Februari 2009].

George, D. dan Mallery. 2003. SPSS for Windows step by step : A simple Guide and reference 11.0 Update. Allyn and Bacon. Boston.

Joreskog, K.G dan P Sorbom.1996. Lisrel 8.51 : User's Reference Guide. Scientific Software International. Chicago.

Kerlinger. Fred N. 1990. Metodologi Penelitian Behaviour. Edisi Terjemahan. Yogyakarta. UGM University Press.

Kuswadi.2004. Cara Mengukur Kepuasan Karyawan. Penerbit Gramedia Pustaka Utama. Jakarta.

Umar. H. 2005. Riset Sumber Daya Manusia dalam Organisasi. PT Gramedia Pustaka Utama. Jakarta.

Wijanto Hari, Setyo, 2008. Structural Equation Modelling dengan Lisrel 8.8 Konsep Tutorial. PT. Graha Ilmu. Yogyakarta. 